\title{
Erratum to: Sunitinib Possible Sex-Divergent Therapeutic Outcomes
}

\author{
Ignacio Segarra $^{1}$ (1) $\cdot$ Pilar Modamio $^{1} \cdot$ Cecilia Fernández $^{1} \cdot$ Eduardo L. Mariño $^{1}$
}

Published online: 17 August 2016

(C) Springer International Publishing Switzerland 2016

\section{Erratum to: Clin Drug Investig DOI 10.1007/s40261-016-0428-5}

In the original publication, some errors are found and the following corrections should be noted:

Section 4, 4th paragraph, 1st sentence, which previously read:

The lower sunitinib hepatic exposure in female mice may anticipate both, the lesser susceptibility to toxicity observed of male patients [32], and the higher incidence ( $p=0.016)$ of $\geq 3$ grade adverse events $[14,15]$ and risk $(p=0.04)$ of thrombocytopenia [16] in female patients.

Should read:

The lower sunitinib hepatic exposure in male mice may anticipate both, the lesser susceptibility to toxicity observed of male patients [32], and the higher incidence $(p=0.016)$ of $\geq 3$ grade adverse events $[14,15]$ and risk $(p=0.04)$ of thrombocytopenia [16] in female patients.

Section 4.1, 1st paragraph, 4th sentence, which previously read:

In fact, $32 \%$ of patients discontinued sunitinib treatment because of a lack of efficacy [35] and this percentage increased to $49 \%$ in the main clinical trial [24].

Should read:

In fact, $32 \%$ of patients discontinued sunitinib treatment because of a lack of efficacy [35] and this percentage increased to $39 \%$ in the main clinical trial [24].

The online version of the original article can be found under doi:10. 1007/s40261-016-0428-5.

Ignacio Segarra

segarra100@gmail.com

1 Clinical Pharmacy and Pharmacotherapy Unit, Department of Pharmacy and Pharmaceutical Technology, Faculty of Pharmacy, University of Barcelona, Avn. Joan XXIII, s/n, 08028 Barcelona, Spain 